\title{
Atmospheric Duct Detection Using Wind Profiler Radar and RASS
}

\author{
Hua Wang, Shipeng Su, Haichuan TANG, AND Lin JiAO \\ Dalian Naval Academy, Dalian, China \\ YUNBO LI \\ Navy Marine Hydrometeorological Center, Beijing, China
}

(Manuscript received 25 January 2018, in final form 12 January 2019)

\begin{abstract}
A method of detecting atmospheric ducts using a wind profiler radar (WPR) and a radio acoustic sounding system (RASS) is proposed. The method uses the RASS to measure the virtual temperature profile and calculate the Brunt-Väisälä frequency; it also uses the WPR to measure the spectral width of the atmosphere and the atmospheric refractive index structure constant. Then the profile of the atmospheric refractive index gradient and modified refractivity are calculated using virtual temperature, spectral width, and the atmospheric refractive index structure constant. Finally, the height and intensity of the atmospheric duct are calculated to achieve continuous monitoring of the atmospheric duct. To verify the height and intensity of the atmospheric duct, comparison experiments between WPR-RASS and radiosondes were carried out from June 2014 to June 2015 in Dalian, Liaoning Province, China. The results show that the profile of modified refractivity by WPR-RASS has exactly the same trend as the radiosondes, the two methods have a good consistency, and the atmospheric duct value from WPR-RASS is in good agreement with that from radiosondes.
\end{abstract}

\section{Introduction}

Atmospheric radio wave ducting, which has a significant influence on electromagnetic wave propagation (Dockery 1988), is a common phenomenon in some areas (Abdul-Jauwad et al. 1991; Babin 1996); the probability of its occurrence is mainly related to the geographical position, season, and weather systems of the area. An atmospheric duct has significant influence on electronic equipment such as radars and communication equipment. It causes surveillance radar, navigation radar, and other radars over-the-horizon detection, increases radar clutter, and causes the appearance of such phenomena as over-the-horizon communication in VHF communication equipment. In particular, a surface duct has a greater impact on shipboard or ground-based electronic equipment. A surface duct is a grounded atmospheric duct (Babin and Rowland 1992; Babin 1996; Brooks et al. 1999); during the advection of a warm and dry air mass to the cold and wet sea surface, an atmospheric layer of inverse temperature and sharply declining humidity is formed, thus forming a surface duct.

Corresponding author: Dr. Hua Wang, dlwhua@sina.com
The detection of atmospheric ducts is very important for research of the formation mechanism and characteristics of atmospheric ducts. Radiosondes are often used to detect atmospheric ducts (Patterson 1982; Babin 1996; Mentes and Kaymaz 2007). In recent years, the vertical resolution of radiosonde data can reach the meter level. Hayton and Craig (1997) used WMO radiosonde data to analyze the distribution of atmospheric ducts worldwide. However, radiosondes are unable to measure atmospheric ducts continuously. In addition, the sounding balloons drift downwind; thus, the values measured are not at the same position. The use of aircraft measurements is another effective method of atmospheric duct detection, including the use of helicopters to measure atmospheric temperature, humidity, and pressure to calculate the modified refractivity (Babin and Rowland 1992; Babin 1996), and the use of aircraft to take zigzag routes to measure atmospheric ducts (Brooks et al. 1999). Using aircraft to measure atmospheric ducts has similar shortcomings as radiosondes. A low-altitude rocket is a convenient atmospheric duct measurement device used on board. In addition, there is also a method for measuring the atmospheric 
duct by a tethered sounding balloon, but the measurement height by this method is limited to the boundary layer. All these methods have inevitable shortcomings: 1) unable to be observed continuously; 2) the equipment is complicated to use and inconvenient; 3) some measurement methods are lossy or less economical, such as the use of radiosondes and sounding rockets. Therefore, it is desirable to find a new remote sensing method to monitor atmospheric ducts, which can continuously observe atmospheric ducts without using sounding equipment.

Wind profiler radar (WPR) can measure the wind field, spectral width and volume refractivity (Tatarski 1961), atmospheric refractive index structural constant (VanZandt et al. 1978; Ruan et al. 2008), etc. The virtual temperature of the atmosphere could be measured if equipped with a radio acoustic sounding system (RASS) (Matuura et al. 1986; May et al. 1989; Tsuda et al. 1994). In this paper, WPR with RASS is used to measure the profile of atmospheric virtual temperature, spectral width, and the atmospheric refractive index structure constant; the Brunt-Väisälä frequency, the turbulence dissipation rate, and the atmospheric refractive index gradient profile are calculated, and then the profile of atmospheric modified refractivity is calculated to get the atmospheric duct value. To verify the height and intensity of the atmospheric duct, comparison experiments between WPRRASS and radiosondes were carried out from June 2014 to June 2015 in Dalian, Liaoning Province, China. The difference of the atmospheric refractivity gradient and the atmospheric modified refractivity between the two methods is analyzed.

\section{Method}

\section{a. Virtual temperature}

Virtual temperature is measured by RASS; RASS has been used for 30 years for the purpose of getting highresolution profiles of tropospheric virtual temperature $T_{v}$ (Matuura et al. 1986; May et al. 1989; Tsuda et al. 1994). The sound source of the RASS is located near the antenna of the WPR; the sound emitted by the sound source changes the atmospheric refractivity of the surrounding air. When the electromagnetic waves emitted by the WPR measure these areas, backscattering occurs; thus, the WPR measures this part of the energy. When these refractivity disturbances propagate upward at the local sound speed, WPR can measure the sound speed at different heights. The $T_{v}$ is calculated according to the relationship between sound speed and temperature and is corrected according to the relation between vertical wind speed and virtual temperature (Angevine et al.
1994; Alexander and Tsuda 2008); $T_{v}$ is determined in each profiler gate by sound speed $c_{a}$ and vertical wind speed $w$ :

$$
T_{v}=\frac{\left(c_{a}-w\right)^{2}}{20.046^{2}} .
$$

The $w$ is measured by WPR; upward the sign is negative, and downward the sign is positive. Because the sound source is spreading out, the sign of $c_{a}$ is negative.

\section{b. Brunt-Väisälä frequency}

Brunt-Väisälä frequency $N_{b}$ is a parameter related to atmospheric static stability; the larger $N_{b}$ is, the greater the stability of the atmosphere, which is calculated by (Alexander and Tsuda 2008) as

$$
\begin{aligned}
N_{b(i)}^{2} & =g \frac{\partial \ln \theta_{v}}{\partial z}=g \lim _{\left(z_{i}-z_{i-1}\right) \rightarrow 0} \frac{\ln \theta_{v(i)}-\ln \theta_{v(i-1)}}{z_{i}-z_{i-1}} \\
& \approx g \frac{\ln \theta_{v(i)}-\ln \theta_{v(i-1)}}{z_{i}-z_{i-1}} .
\end{aligned}
$$

Here $\theta_{v}$ is virtual potential temperature, $z$ is height, $g$ is gravitational acceleration, and $\theta_{v}$ is calculated by $T_{v}$ (Sheng et al. 2013):

$$
\theta_{v}=T_{v}\left(\frac{P_{0}}{P}\right)^{0.286} .
$$

Here $P_{0}$ is $1000 \mathrm{hPa}$, and $P$ is the atmospheric pressure at the height of the $T_{v}$ and is calculated by the barometric height formula (Sheng et al. 2013):

$$
\ln P=\ln P_{1}-\frac{g\left(h-h_{1}\right)}{287 T_{v}} .
$$

Here, $h_{1}$ is the height of the radar antenna above sea level, $P_{1}$ is the pressure at $h_{1}, g$ is $9.8 \mathrm{~m} \mathrm{~s}^{-2}, h$ is the height of each level, $P$ is the pressure at $h$, and $T_{v}$ is the virtual temperature at $h$.

\section{c. Turbulence dissipation rate}

Turbulence dissipation rate $\varepsilon$ is an important parameter characterizing the turbulent environment; Hocking (1985) pointed out the relationship between turbulent dissipation rate $\varepsilon$ and spectral width $\sigma^{2}$ :

$$
\varepsilon=b N_{b} \sigma^{2} .
$$

Here $N_{b}$ is Brunt-Väisälä frequency and $b$, a dimensionless constant, is 0.6 (Carol and Lakshmi 2008). Spectral width $\sigma^{2}$ is measured by the WPR. 


\section{d. Refractive index structure constant}

In theory, in the local uniform, isotropic turbulence inertial subregion, the ability of the turbulent motion of clear air to cause backscattering of electromagnetic waves is expressed by the refractive index structure constant $C_{n}^{2}\left(\mathrm{~m}^{-2 / 3}\right) ; C_{n}^{2}$ is exponentially distributed from the bottom to the top within the range of $10^{-13}-10^{-17}$ in the troposphere. The trend of $C_{n}^{2}$ is decreasing as the height increases; $C_{n}^{2}$ is related to the volume reflectivity $\eta$ (Tatarski 1961):

$$
\eta=0.38 C_{n}^{2} \lambda^{-1 / 3} .
$$

Here $\lambda$ is the wavelength of electromagnetic wave; the unit of $\eta$ is per meter $\left(\mathrm{m}^{-1}\right)$. The scattering of electromagnetic waves by atmospheric turbulence is similar to the scattering of electromagnetic waves by clouds; it is a dispersion target. The relation between the backscatter power of a radar and $\eta$ is (Cohn 1995)

$$
P_{r}=\frac{P_{t} G L^{2} \lambda^{2} \theta^{2} h \eta}{1024 \pi^{2}(\ln 2) R^{2}}
$$

Here $p_{t}$ is the radar transmitted power, $p_{t}$ the radar received power, $R$ the range to the target, $G$ the antenna gain, $L$ the radar system loss, $\lambda$ the radar wavelength, $\theta$ the radar beamwidth, and $h$ the transmitted pulse length. Place Eq. (6) into Eq. (7) to derive the wind profiler radar received power method for estimating the refractive index structure constant $C_{n}^{2}$ :

$$
C_{n}^{2}=\frac{P_{r} R^{2}}{1.085 \times 10^{-4} \lambda^{5 / 3} P_{t}(h / 2) G L^{2} \theta^{2}} .
$$

According to the relationship between $P_{r}$ and the signal-to-noise ratio $S_{\mathrm{NR}_{0}}$ (Ding and Geng 2004), the above equation is written as

$$
C_{n}^{2}=\frac{S_{\mathrm{NR}_{0}} k T_{\mathrm{sys}} B_{0} R^{2}}{1.085 \times 10^{-4} \lambda^{5 / 3} P_{t}(h / 2) G L^{2} \theta^{2}} .
$$

Here $k=1.38 \times 10^{-23}$ is the Boltzmann constant, $T_{\text {sys }}$ is the system noise temperature, and $B_{0}$ is the receiver's bandwidth. The estimation equation of the refractive index structure constant is converted to

$$
C_{n}^{2}=C S_{\mathrm{NR}_{0}} R^{2} .
$$

The $C$ is related to the parameters of the radar:

$$
C=\frac{k T_{\text {sys }} B_{0}}{1.085 \times 10^{-4} \lambda^{5 / 3} P_{t}(h / 2) G L^{2} \theta^{2}} .
$$

\section{e. Refractive index gradient}

The propagation of electromagnetic waves in the atmosphere is usually described by atmospheric refractive index $n$. The refractive index gradient can represent the propagation path of the electromagnetic wave in the atmosphere; WPR-RASS is used to calculate the refractive index gradient. Tusda et al. (2001) studied the WPR to measure atmospheric turbulence; the relationship between the refractive index gradient $d n / d z$ and the refractive index structure constant $C_{n}^{2}$, the Brunt-Väisälä frequency $N_{b}$, and the turbulent dissipation rate $\varepsilon$ is

$$
\left(\frac{d n}{d z}\right)^{2}=a C_{n}^{2} N_{b}^{2} \varepsilon^{-2 / 3} .
$$

Here $a$ is a constant determined by radar parameters. The sign of $d n / d z$ directly influences the change tendency of refractive index; Tusda et al. (2001) pointed out the sign is determined by $N_{b}^{2}$ threshold methods. Based on the statistical analysis of this type of WPRRASS measurement data, the empirical threshold is $1.0 \times 10^{-5} \mathrm{rad}^{2} \mathrm{~s}^{-2}$. If $N_{b}^{2}$ is less than this value, it is positive; otherwise, it is negative. The above equation can be converted to

$$
\frac{d n}{d z}=\left\{\begin{array}{cc}
a^{1 / 2}\left(C_{n}^{2}\right)^{1 / 2} N_{b} \varepsilon^{-1 / 3}, & N_{b}^{2}<1.0 \times 10^{-5}, \\
-a^{1 / 2}\left(C_{n}^{2}\right)^{1 / 2} N_{b} \varepsilon^{-1 / 3}, & N_{b}^{2} \geq 1.0 \times 10^{-5} .
\end{array}\right.
$$

The relationship between the refractivity gradient and the refractive index gradient is

$$
\frac{d N}{d z}=\frac{d n}{d z} \times 10^{6} .
$$

The atmospheric refractivity gradient is calculated using the above method, and its accuracy is verified by radiosonde measurements. The equation for calculating atmospheric refractivity using radiosonde measurements is (Bean and Dutton1968)

$$
N(z)=\frac{77.6 P(z)}{T(z)}-\frac{5.6 e(z)}{T(z)}+3.75 \times 10^{5} \frac{e(z)}{T^{2}(z)} .
$$

Here $P$ is air pressure, $T$ is absolute temperature, $e$ is partial pressure of water vapor, and then the atmospheric refractivity gradient is calculated based on $N$.

\section{f. Atmospheric ducts}

Atmospheric ducts in the atmosphere are determined by the modified refractivity gradient method. The relationship between modified refractivity $M$ ( $M$ units) 
and refractivity $N$ is the following (Bean and Dutton 1968):

$$
M=N+\frac{z}{a} \times 10^{6}=N+0.157 z .
$$

The $a$ is the radius of Earth; here the value is $6371 \mathrm{~km}$, the curvature of Earth is $1 / a=0.157 \times 10^{-3} \mathrm{~km}^{-1}$, and $z(\mathrm{~m})$ is height above sea level. The relationship between the modified refractivity gradient $d M / d z$ and refractivity gradient $d N / d z$ is

$$
\frac{d M}{d z}=\frac{d N}{d z}+0.157
$$

When $d M / d z<0(d N / d z<-0.157)$, trapped refraction appears (Turton et al. 1988); the layer of $d M / d z<0$ is the trapped layer, which means the emergence of the atmospheric duct. The intensity of the atmospheric duct is expressed by $\Delta M$; it represents the ability of the atmosphere to trap electromagnetic waves. The $\Delta M=M_{2}-M_{1}$; here $M_{2}$ is the modified refractivity of the top of the trapped layer, $M_{1}$ is the modified refractivity of the bottom of the trapped layer, and the height of $M_{2}$ is the height of the top of the atmospheric duct. Make a line perpendicular to the ground at $M_{2}$ in the profile of modified refractivity and intersect the line at a point of the profile of modified refractivity; the height of the intersection is the height of the bottom of the duct.

\section{WPR-RASS detection atmospheric duct experiment}

To verify the height and intensity of the atmospheric duct, comparison experiments between WPR-RASS and radiosondes were carried out from June 2014 to June 2015 in Dalian. During the period of observation, 16 experiments were carried out; 2 of them were under conditions of atmospheric ducts. The intensity of these two ducts was weak. The two times were 1915 LT 17 October 2014 and 1910 LT 1 June 2015.

The GTS1 Digital Radiosonde produced by Shanghai Changwang Meteotech Co., Ltd., was used in these experiments. The radiosonde launch site was $3 \mathrm{~km}$ away from the WPR-RASS; the WPR-RASS site was near the beach. The terrain elevation between the two sites was about $60 \mathrm{~m}$. The observations of radiosondes and WPRRASS were carried out at the same time.

Radiosondes took approximately $20 \mathrm{~min}$ to ascend to $5.7 \mathrm{~km}$. To compare the WPR-RASS and radiosonde data, WPR-RASS data were extracted from the time of each launch until $20 \mathrm{~min}$ after. During this time, wind velocity is measured first, and the virtual temperature is
TABLE 1. The parameters of CFL-16 WPR.

\begin{tabular}{lc}
\hline Frequency $(\mathrm{MHz})$ & 445 \\
Height range $(\mathrm{m})$ & $150-3225$ \\
Pulse width $(\mu \mathrm{s})$ & 0.5 \\
Pulse repetition period $(\mu \mathrm{s})$ & 60 \\
Peak power $(\mathrm{kW})$ & 20 \\
Coherent integration & 200 \\
No. of FFT points & 256 \\
Incoherent integration & 5 \\
Range gate $(\mathrm{m})$ & 75 \\
No. of gates & 42 \\
No. of beams & 5 \\
Mode & Low \\
\hline
\end{tabular}

measured about four minutes later. The WPR-RASS altitude above sea level was $70.8 \mathrm{~m}$; the parameters of WPR-RASS are listed in Tables 1 and 2. In lowdetection mode, the range of detection height for the WPR was from 150 to $3225 \mathrm{~m}$, the range gate was $75 \mathrm{~m}$, the number of fast Fourier transforms was 256, and the WPR had five beams: one vertical beam and four tilted beams with a zenith angle of $14.2^{\circ}$. The $T_{v}$ was measured by RASS, the height range of the $T_{v}$ was from 150 to $3300 \mathrm{~m}$, and the range gate of $T_{v}$ is $75 \mathrm{~m}$ from 150 to $1050 \mathrm{~m}$ and $150 \mathrm{~m}$ from 1350 to $3300 \mathrm{~m}$. To align the height of $T_{v}$ with the height of the WPR measurement data, these $T_{v}$ need to be interpolated to the height corresponding to the measurement data of the WPR.

The $T_{v}$ profile calculated from the radiosonde is shown as a solid line in Fig. 1a at 1915 LT 17 October 2014. The $T_{v}$ profile from the WPR-RASS is shown as a dashed line in the figure. The $T_{v}$ from WPR-RASS is in good agreement with that from the radiosonde. Since the range gate of RASS is $75 \mathrm{~m}$, and the vertical interval of the measured data of the radiosonde is about $10 \mathrm{~m}$, even though the data measured from the WPR-RASS and the radiosonde are exactly the same, the profiles of the two will be different. Figure $2 b$ shows the profile of modified refractivity calculated from the radiosonde (solid line). The figure shows two elevated ducts. The top height of the first elevated duct is $285 \mathrm{~m}$, and the duct intensity $\Delta M=-1.4$; the top

TABLE 2 . The parameters of RASS.

\begin{tabular}{lc}
\hline \hline \multicolumn{2}{c}{ Acoustic source } \\
\hline Transmitter & Hyperbolic horn speaker \\
Wave & CW \\
Repetition (s) & 1 \\
& \\
& $T_{v}$ by RASS \\
Height range (m) & $150-3300$ \\
Number of gates & 27 \\
Range gate (first 13 levels) (m) & 75 \\
\hline
\end{tabular}



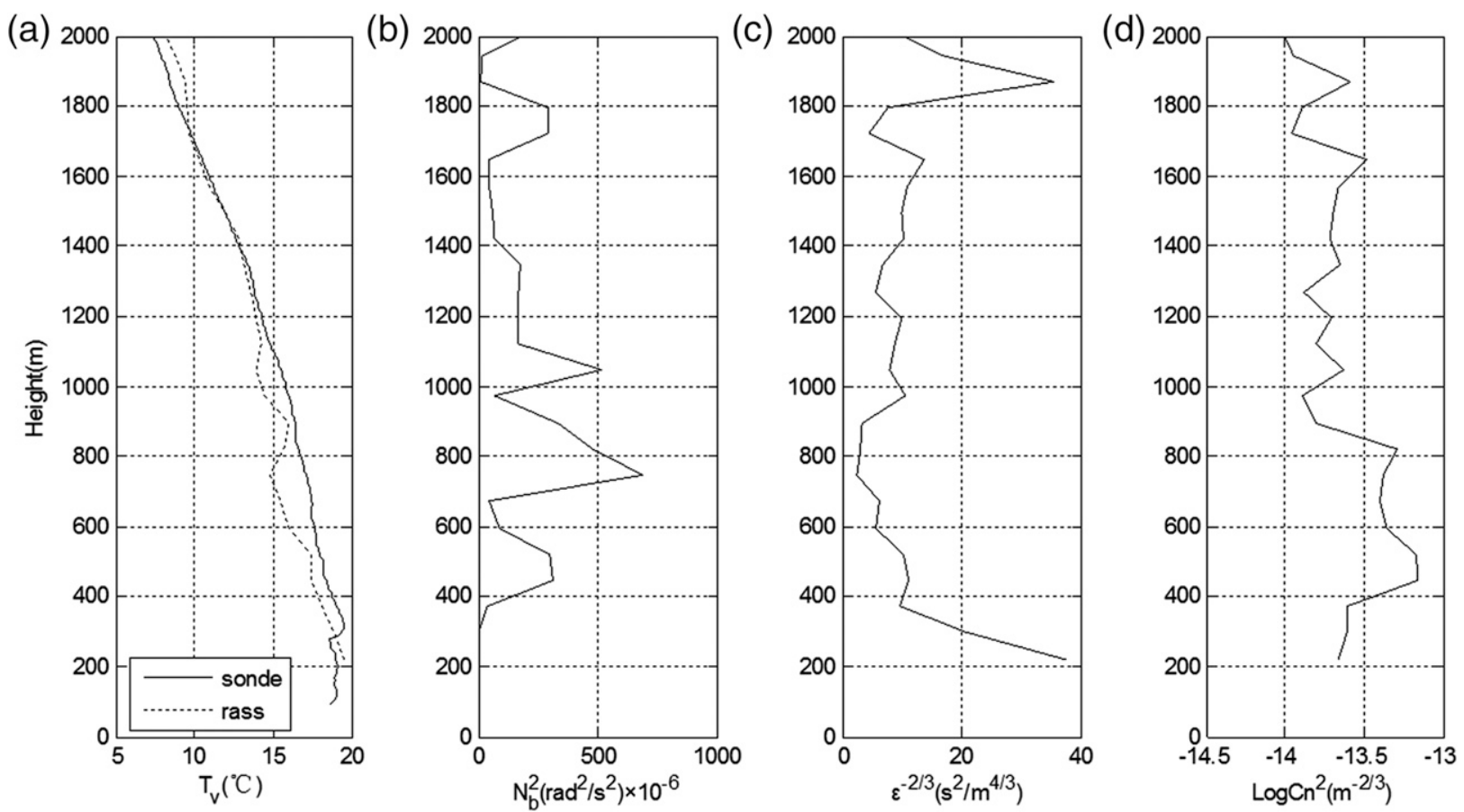

FIG. 1. (a) Comparison of $T_{v}$ from RASS (dashed line; ${ }^{\circ} \mathrm{C}$ ) and the radiosonde (solid line). The profiles of (b) $N_{b}^{2}$, (c) $\varepsilon^{-2 / 3}$, (d) $\log C_{n}^{2}$ calculated from the WPR-RASS at 1915 LT 17 Oct 2014.

height of the second elevated duct is $491 \mathrm{~m}$, and the duct intensity $\Delta M=-1.0$.

The profile of Brunt-Väisälä frequency squared $N_{b}^{2}$, turbulence dissipation rate $\varepsilon$, and the atmospheric refractive index structure constant $C_{n}^{2}$ calculated from the WPR-RASS are also shown in Fig. 1. Figure $1 b$ is the profile of $N_{b}^{2}$. This value shows the gradient of virtual potential temperature; the greater the gradient of virtual
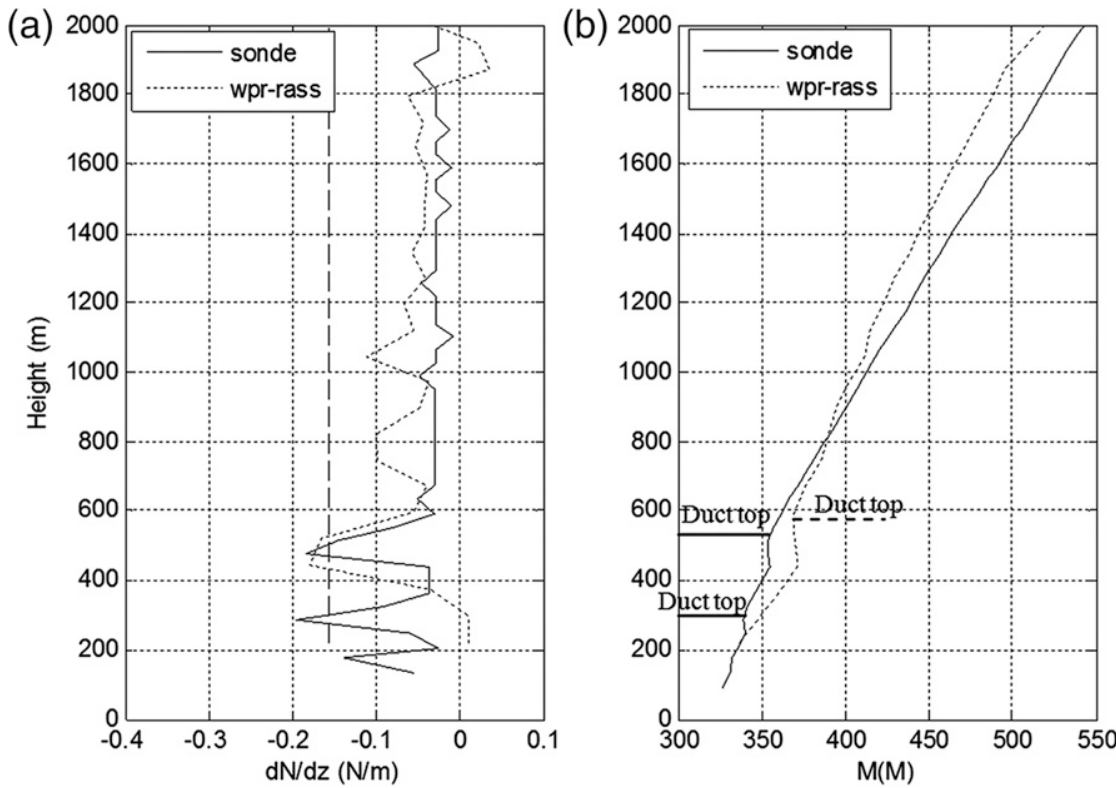

FIG. 2. Comparison of (a) the atmospheric refractivity gradient and (b) $M$ from WPR-RASS (dashed line) and the radiosonde (solid line) at 1915 LT 17 Oct 2014. 


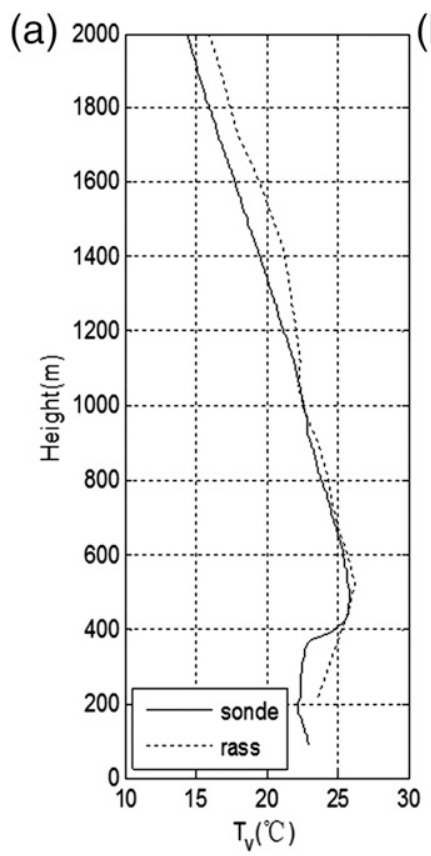

(b)

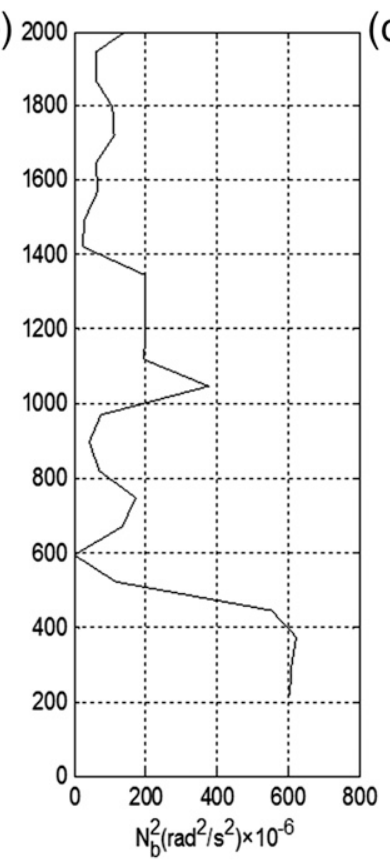

(c)

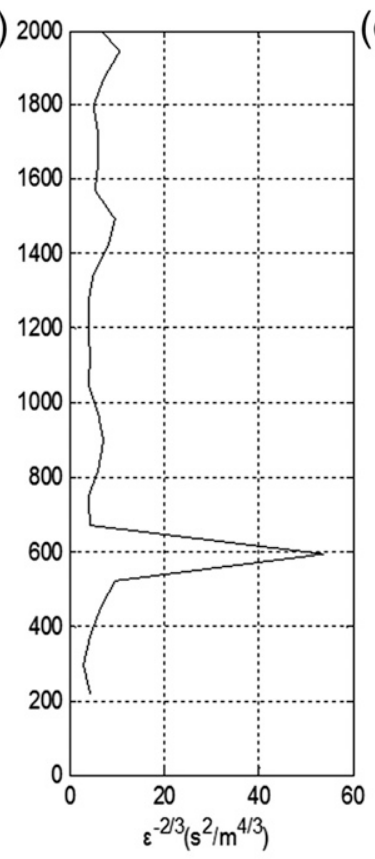

(d)

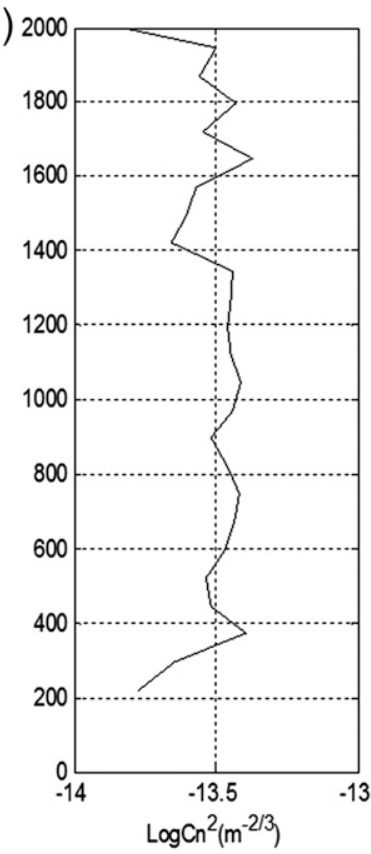

FIG. 3. (a) Comparison of $T_{v}$ from RASS (dashed line; ${ }^{\circ} \mathrm{C}$ ) and the radiosonde (solid line). The profiles of (b) $N_{b}^{2}$, (c) $\varepsilon^{-2 / 3}$, (d) $\log C_{n}^{2}$ calculated from the WPR-RASS at 1910 LT 1 Jun 2015.

potential temperature is, the greater $N_{b}^{2}$. At that moment, there were four large-value areas at heights of $500,750,1050$, and $1750 \mathrm{~m}$, respectively. Figure $1 \mathrm{c}$ shows $\varepsilon$ as a function of altitude, and there are two large-value zones near heights of 220 and $1870 \mathrm{~m}$. Figure $1 \mathrm{~d}$ is the profile of $C_{n}^{2}$. The general trend is to decrease with height, and $C_{n}^{2}$ reaches its maximum near $500 \mathrm{~m}$.

According to Eq. (12), $(d n / d z)^{2}$ is determined by the product of $N_{b}^{2}, C_{n}^{2}$, and $\varepsilon^{-2 / 3}$. The $N_{b}^{2}$ varies the most with height, followed by $\varepsilon^{-2 / 3}$, so the change of $(d n / d z)^{2}$ is mainly determined by $N_{b}^{2}$. The profile of $d N / d z$ from WPR-RASS is shown by the dashed line in Fig. 2a. The refractivity gradient $d N / d z<-0.157$ at the height of 445.8 and $520.8 \mathrm{~m}$ indicates the emergence of the atmospheric duct, according to the atmospheric duct determination method. The line $d N / d z-0.157$ is shown by a long dashed line in the figure.

When the modified refractivity profile is calculated from WPR-RASS data, the first layer of modified refractivity is calculated approximately by Eqs. (15) and (16), the humidity of the first layer is calculated from WPR-RASS data by the method of Tsuda et al. (2001), and the air pressure of the first layer is calculated by ground pressure, which was measured at the WPRRASS site and the height of first layer. The profile of modified refractivity is calculated from the refractivity gradient profile as shown by the dashed line in Fig. $2 b$, the top height of the duct is $595.8 \mathrm{~m}$ in the figure, and duct intensity $\Delta M=-11.8$. The profile of modified refractivity from the radiosonde is also shown by the solid line in the figure. There is a good consistency between the two profiles; both these methods have detected the atmospheric duct. The height of the duct is similar, except that the duct intensity from WPR-RASS is stronger. In addition, the profile of modified refractivity from WPR-RASS does not show a duct at $285 \mathrm{~m}$. This is mainly caused by the accuracy of RASS near ground due to the presence of the ground clutter which affects the accuracy of the $T_{v}$. It can also be seen from Fig. 2b that the modified refractivity from WPR-RASS is generally small; this is mainly determined by the empirical threshold of $N_{b}^{2}$.

Another atmospheric duct was detected in summer. The $T_{v}$ profile calculated from the radiosonde is shown as a solid line in Fig. 3a at 1910 LT 1 June 2015. The $T_{v}$ profile from the WPR-RASS is shown as a dashed line in the figure. Both of the $T_{v}$ profiles have inversion layers, and their trends are exactly the same. The $T_{v}$ profile from WPR-RASS increased from $23.7^{\circ} \mathrm{C}$ at $220.8 \mathrm{~m}$ to $26.2^{\circ} \mathrm{C}$ at $520.8 \mathrm{~m}$, and the intensity of the inversion temperature is $0.83^{\circ} \mathrm{Chm}^{-1}$. The $T_{v}$ profile from the radiosonde increased from $22.2^{\circ} \mathrm{C}$ at $197 \mathrm{~m}$ to $25.9^{\circ} \mathrm{C}$ at $497 \mathrm{~m}$, and the intensity of the inversion temperature is $1.2^{\circ} \mathrm{Chm}^{-1}$. Both of 

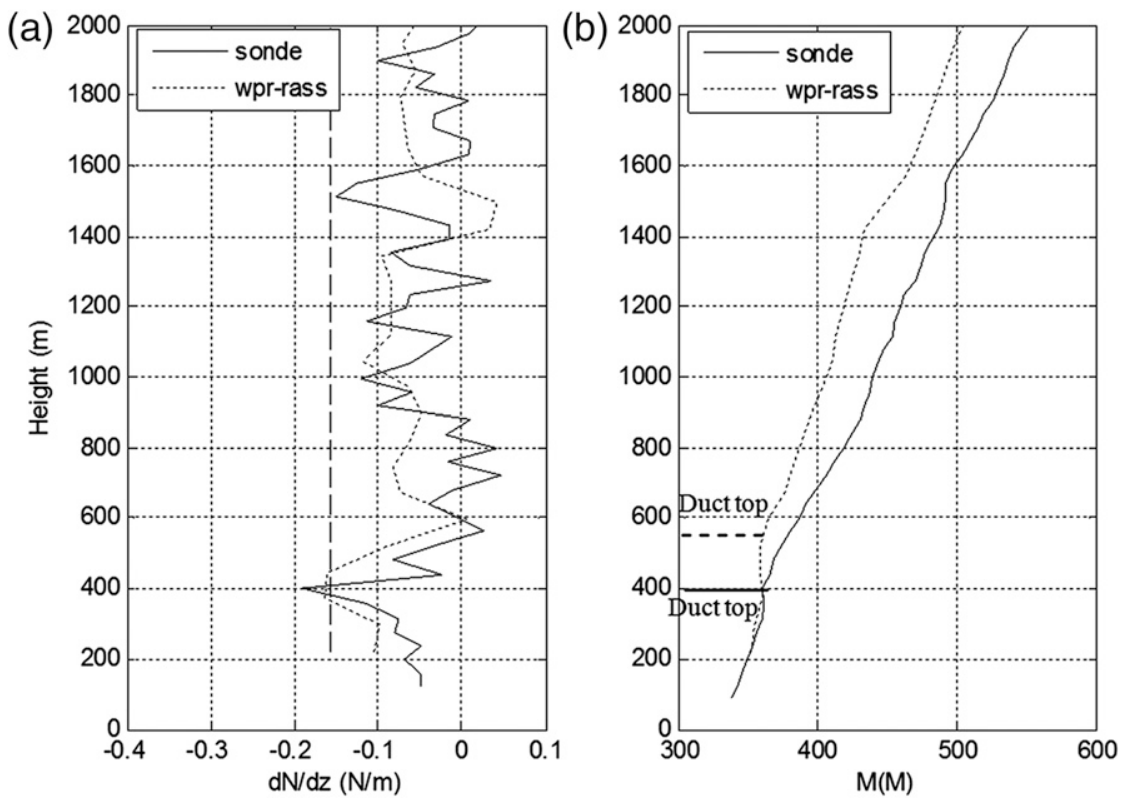

FIG. 4. Comparison of (a) the atmospheric refractivity gradient and (b) $M$ from WPR-RASS (dashed line) and the radiosonde (solid line) at 1910 LT 1 Jun 2015.

them are in good agreement in the vicinity of the inversion layer, and the $T_{v}$ above the inversion layer is also in good agreement. Figure $4 \mathrm{~b}$ shows the profile of modified refractivity calculated from the radiosonde (solid line). The figure shows an elevated duct, the top height of the duct is $389 \mathrm{~m}$, and the duct intensity $\Delta M=-1.4$.

The profile of $N_{b}^{2}, \varepsilon$, and the $C_{n}^{2}$ calculated from the WPR-RASS are shown in Fig. 3. Figure $3 \mathrm{~b}$ is the profile of $N_{b}^{2}$. At that moment, there are two large-value areas at the height of $220.8-445.8$ and $1046 \mathrm{~m}$, respectively. Figure $3 \mathrm{c}$ shows the $\varepsilon^{-2 / 3}$ as a function of altitude, and there is a large-value zone near the height of $595 \mathrm{~m}$. Figure $3 \mathrm{~d}$ is a profile of $C_{n}^{2}$. The general trend is also decreasing with height. The reduction rate is weaker than the calculated value on 14 October 2014. At the height of $370.8 \mathrm{~m}$, the $C_{n}^{2}$ has a large value.

The profile of $d N / d z$ from WPR-RASS is shown by the dashed line in Fig. 4a. At the heights of 370.8 and $445.8 \mathrm{~m}, d N / d z$ is -0.164 and -0.162 , respectively. Both of these are less than -0.157 , indicating the presence of the atmospheric duct. The profile of modified refractivity calculated from the refractivity gradient profile is shown by the dashed line in Fig. 4b. The top height of the duct is $520.8 \mathrm{~m}$, and the duct intensity $\Delta M=-1.0$. The profile of modified refractivity from the radiosonde is shown by the solid line in the figure. It can be seen that the trends of the modified refractivity calculated by the two methods are exactly the same and have good consistency. The modified refractivity from WPR-RASS is slightly less than that from the radiosonde, the duct height from WPR-RASS is slightly higher than the height from radiosonde, and the duct intensity is slightly weaker than the result from radiosonde.

\section{Discussion and conclusions}

WPR-RASS is used to detect atmospheric ducts. Two examples from different seasons show that the profile of modified refractivity and the atmospheric duct value by this method is consistent with the method by radiosondes. The validity of this method has been proved preliminarily, and the main conclusions are summarized below:

1) The method of detecting atmospheric ducts using WPR-RASS is to measure the profile of $T_{v}$ by the RASS and the profile of $\sigma^{2}$ and $S_{\mathrm{NR} 0}$ by WPR; calculate $N_{b}^{2}, \varepsilon, C_{n}^{2}$, and atmospheric refractive index gradient $d n / d z$; and then calculate the profile of modified refractivity according to the atmospheric refractive index gradient. Finally, the atmospheric duct is determined according to the decision method of the atmospheric refractivity gradient, and the height and intensity of the atmospheric duct is calculated according to the profile of modified refractivity.

2) The accuracy of atmospheric duct detection is mainly determined by the accuracy of the refractive index 
gradient. The value of the refractive index gradient is determined by $N_{b}^{2}, \varepsilon$, and $C_{n}^{2}$. Among them, the $N_{b}^{2}$ plays a major role, so the accuracy of $T_{v}$ is very important for atmospheric duct detection.

3) The method of detecting an atmospheric duct by WPR-RASS sometimes leads to missing ducts. This mainly occurs at times when the $T_{v}$ deviation is larger or the measurement value is missing. There are three main conditions: 1) the wind speed is higher (>10 $\mathrm{m} \mathrm{s}^{-1}$ for CFL-16); 2) humidity changes with height are rather significant; 3 ) close to the ground, there is influence of noise affecting the signal-tonoise ratio, which affects the $T_{v}$ measurement; it is particularly obvious at the $T_{v}$ of the bottom two layers. In addition, the CFL-16 WPR has a slightly larger spectral width than other WPRs. This leads to larger $\varepsilon$ and smaller absolute values of the atmospheric refractive index gradient, thus leading to the duct being missed. In addition, because the measurement of sound speed and wind velocity is not completely simultaneous in the experiment, there are still vertical wind errors.

4) The vertical resolution of WPR-RASS data is $75 \mathrm{~m}$ in the low mode of CFL-16. The low vertical resolution of data has led to deviations of the measured atmospheric data from the reality, leading to errors in detecting atmospheric duct, or even missing the duct.

Continuous automatic detection of the atmospheric duct is of great significance for the study of the phenomenon and the mechanism of the atmospheric duct. It is also important to study the application of atmospheric ducts. To improve this method, the following research will be carried out: 1) studying how to improve the accuracy of $T_{v}$ measured by RASS and reduce the absence of measurement data; 2) studying methods to reduce clutter; 3 ) acquiring and accumulating $N_{b}^{2}$ and atmospheric refractive index gradient data in different seasons, adding data samples, and analyzing the relationship between the two, in order to determine the impact of different seasons and different weather conditions on the $N_{b}^{2}$ threshold; 4) improving the calculation accuracy of the turbulent dissipation rate by WPR; 5) improving the vertical resolution of WPRRASS data so that the vertical resolution of data is no more than $50 \mathrm{~m}$; and 6) measuring sound speed and wind velocity simultaneously to modify wind error.

Acknowledgments. This research is supported by the National Natural Science Foundation of China under Grant 41276019. We deeply thank Dalian Meteorological Bureau for providing us with radiosonde data during the WPR-RASS experiments.

\section{REFERENCES}

Abdul-Jauwad, S. H., P. Z. Khan, and T. O. Halawani, 1991: Prediction of radar coverage under anomalous propagation conditions for a typical coastal site: A case study. Radio Sci., 26, 909-919, https://doi.org/10.1029/91RS00092.

Alexander, S. P., and T. Tsuda, 2008: High-resolution radio acoustic sounding system observations and analysis up to 20 km. J. Atmos. Oceanic Technol., 25, 1383-1396, https:// doi.org/10.1175/2007JTECHA983.1.

Angevine, W. M., W. L. Ecklund, D. A. Carter, K. S. Gage, and K. P. Moran, 1994: Improved radio acoustic sounding techniques. J. Atmos. Oceanic Technol., 11, 42-49, https://doi.org/ 10.1175/1520-0426(1994)011<0042:IRAST>2.0.CO;2.

Babin, S. M., 1996: Surface duct height distributions for Wallops Island, Virginia, 1985-1994. J. Appl. Meteor., 35, 86-93, https://doi.org/ 10.1175/1520-0450(1996)035<0086:SDHDFW >2.0.CO;2.

_ - and J. R. Rowland, 1992: Observation of a strong surface radar duct using helicopter acquired fine-scale radio refractivity measurements. Geophys. Res. Lett., 19, 917-920, https:// doi.org/10.1029/92GL00562.

Bean, B. R., and E. J. Dutton, 1968: Radio Meteorology. Dover, 435 pp. Brooks, I. M., A. K. Goroch, and D. P. Rogers, 1999: Observations of strong radar ducts over the Persian Gulf. J. Appl. Meteor., 38, 1293-1310, https://doi.org/10.1175/1520-0450(1999) 038<1293:OOSSRD > 2.0.CO;2.

Carol, A. C., and K. Lakshmi, 2008: On turbulence and mixing in the free atmosphere inferred from high-resolution soundings. J. Atmos. Oceanic Technol., 25, 833-852, https://doi.org/10.1175/ 2007JTECHA992.1.

Cohn, S., 1995: Radar measurements of turbulence eddy dissipation rate in the troposphere: A comparison of techniques. J. Atmos. Oceanic Technol., 12, 85-95, https://doi.org/10.1175/ 1520-0426(1995)012<0085:RMOTED > 2.0.CO;2.

Ding, L., and F. Geng, 2004: Radar Theory (in Chinese). 3rd ed. Xidian University Press, $59 \mathrm{pp}$.

Dockery, G. D., 1988: Modeling electromagnetic wave propagation in the troposphere using the parabolic equation. IEEE Trans. Antennas Propag., 36, 1464-1470, https://doi.org/10.1109/8.8634.

Hayton, T. G., and K. H. Craig, 1997: Mapping of radiosondederived clear air climatic parameters using neural modelling techniques. 10th Int. Conf. on Antennas and Propagation, Edinburgh, United Kingdom, IEEE, 329-333, https://doi.org/ 10.1049/cp:19970393.

Hocking, W. K., 1985: Measurement of turbulent energy dissipation rates in the middle atmosphere by radar techniques: A review. Radio Sci., 20, 1403-1422, https://doi.org/10.1029/ RS020i006p01403.

Matuura, N., Y. Masuda, H. Inuki, S. Kato, S. Fukao, T. Sato, and T. Tsuda, 1986: Radio acoustic measurement of temperature profile in the troposphere and stratosphere. Nature, 323, 426428, https://doi.org/10.1038/323426a0.

May, P. T., K. P. Moran, and R. G. Strauch, 1989: The accuracy of RASS temperature measurements. J. Appl. Meteor., 28 , 1329-1335, https://doi.org/10.1175/1520-0450(1989)028<1329: TAORTM $>2.0$.CO;2.

Mentes, S. S., and Z. Kaymaz, 2007: Investigation of surface duct conditions over Istanbul, Turkey. J. Appl. Meteor. Climatol., 46, 318-337, https://doi.org/10.1175/JAM2452.1.

Patterson, W. L., 1982: Climatology of marine atmospheric refractive effects: A compendium of the Integrated Refractive effects Prediction System (IREPS) historical summaries. Naval Ocean Systems Center Tech. Doc. 573, 525 pp. 
Ruan, Z., P. He, and R. S. Ge, 2008: Determination of refractive index structure constant with wind profile radar data. Chin. J. Atmos. Sci., 32, 133-140.

Sheng, P., and Coauthors, 2013: Atmospheric Physics (in Chinese). Beijing University Press, $136 \mathrm{pp}$.

Tatarski, V. I., 1961: Wave Propagation in a Turbulent Medium. McGraw Hill, 285 pp.

Tsuda, T., T. Adachi, Y. Masuda, S. Fukao, and S. Kato, 1994: Observations of tropospheric temperature fluctuations with the MU radar-RASS. J. Atmos. Oceanic Technol., 11, 50-62, https:// doi.org/10.1175/1520-0426(1994)011<0050:OOTTFW>2.0.CO;2.
— M. Miyamoto, and J. Furumoto, 2001: Estimation of a humidity profile using turbulence echo characteristics. J. Atmos. Oceanic Technol., 18, 1214-1222, https://doi.org/10.1175/ 1520-0426(2001)018<1214:EOAHPU>2.0.CO;2.

Turton, J. D., D. A. Bennetts, and S F G. Farmer, 1988: An introduction to radio ducting. Meteor. Mag., 117, 245-254.

VanZandt, T. E., J. L. Green, K. S. Gage, and W. L. Clark, 1978: Vertical profiles of refractivity structure constant: Comparison of observations by the Sunset radar with a new theoretical model. Radio Sci., 13, 819-829, https://doi.org/ 10.1029/RS013i005p00819. 